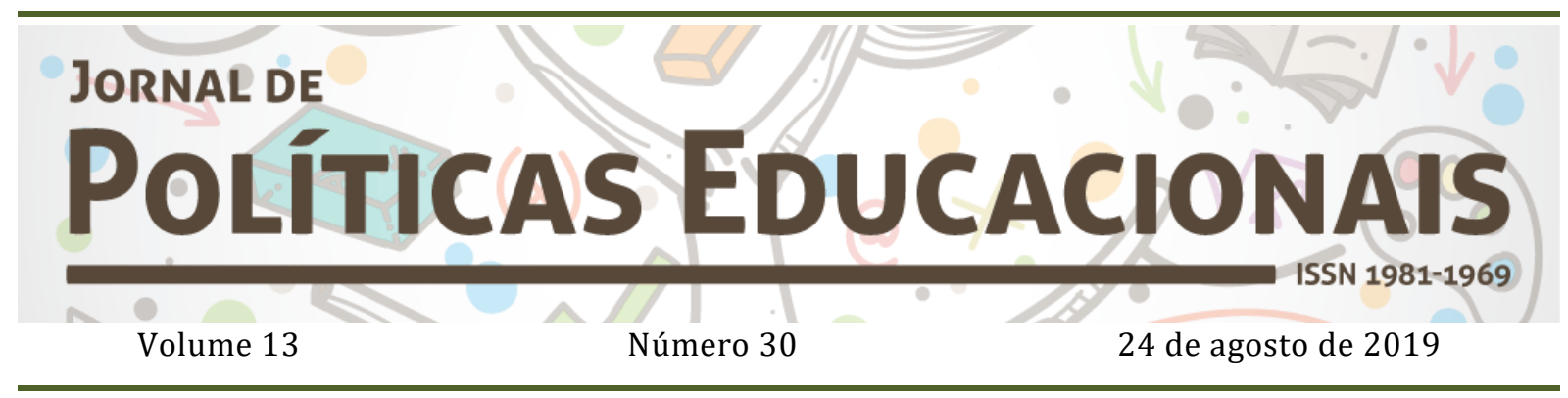

\title{
A gestão da política de socioeducação no Estado do Paraná: repercussões no período de 2007 a 2015
}

\section{The management of socioeducation policy in the state of Paraná: repercussions in the period $2007-2015$}

\section{La gestión de la política socioeducativa en el estado de Paraná: repercusiones en el período 2007-2015.}

\author{
Renata Hoeflich Damaso de Oliveira ${ }^{1}$ \\ Ireni Marilene Zago Figueiredo ${ }^{2}$
}

Citação: OLIVEIRA, Renata Hoeflich Damaso de; FIGUEIREDO, Ireni Marilene Zago. A gestão da política de socioeducação no Estado do Paraná: repercussões no período de 2007 a 2015. Jornal de Políticas Educacionais. V. 13, n. 30. Agosto de 2019.

http:// 10.5380/jpe.v13i0.63693

\begin{abstract}
Resumo:
Este estudo apresenta os resultados da investigação acerca da gestão da Política de Socioeducação do estado do Paraná, no período de 2007 a 2015, considerando a transição do Sistema Estadual de Atendimento Socioeducativo por diferentes secretarias de estado. A metodologia adotada foi a de pesquisa documental e bibliográfica por meio da análise de fontes primárias e secundárias, a qual foi complementada por reflexões advindas da prática profissional vivenciada em uma unidade de atendimento socioeducativo. A análise dos dados demonstrou que, no período de 2007 a 2015, a Política de Socioeducação paranaense apresentou uma lógica centralizada em intervenções direcionadas ao indivíduo em detrimento de ações coletivas. Com as mudanças de locus institucional do Sistema de Atendimento Socioeducativo, ocorreram alterações nas características e destinação de verbas dos programas existentes, o que sugere a descontinuidade dos
\end{abstract}

\footnotetext{
1 Mestre em Educação pela Universidade do Oeste do Paraná - UNIOESTE - PR. Terapeuta Ocupacional na Secretaria de Justiça, Trabalho e Direitos Humanos - SEJU - PR. Orcid: https://orcid.org/0000-0002-11073542. E-mail: renatahdo@gmail.com.

2 Doutora em Educação pela Universidade Estadual de Campinas - UNICAMP - SP. Professora do Colegiado do Curso de Pedagogia e do Mestrado em Educação da Universidade Estadual do Oeste do Paraná UNIOESTE - Campus de Cascavel - PR. Orcid: https://orcid.org/0000-0001-8875-7099 E-mail: irenifigueiredo@hotmail.com.
} 
programas desenvolvidos para a população de adolescentes autores de ato infracional, indicando a adoção de Políticas de Governo e não efetivamente de uma Política de Estado.

Palavras-chaves: Socioeducação. Adolescente em conflito com a lei. Política Social. Paraná.

\begin{abstract}
This study presents the results of a research on the management of the Socio-education Policy of the State of Paraná from 2007 to 2015 taking into account the transition of the State System of Socio-Educational Assistance to different state secretariats. The methodology adopted was that of document and bibliography research - through the analysis of primary and secondary sources - complemented by reflections that arose from the professional experience in a socio educative care unit. The analysis of the data showed that in the period of 2007 to 2015 the Socio-education Policy of Paraná presented a logic centralized in interventions focused on the individual to the detriment of collectivity. With changes in the institutional locus of the SocioEducational Assistance System, there were changes in the characteristics and allocation of funds of the existing programs, which suggests the discontinuity of the programs developed to the population of adolescents who committed an infraction, thus indicating the adoption of Government Policies and not effectively a State Policy.
\end{abstract}

Keywords: Socioeducation. Adolescent in conflict with the law. Social Policy. Paraná.

\title{
Resumen:
}

Este estudio presenta los resultados de la investigación sobre la gestión de la Política de socioeducación del estado de Paraná, de 2007 a 2015, considerando la transición del sistema estatal de asistencia socioeducativa por parte de diferentes secretarías de estado. La metodología adoptada fue la de la investigación documental y bibliográfica, a través del análisis de fuentes primarias y secundarias, complementada por reflexiones derivadas de la práctica profesional experimentada en una unidad de atención socioeducativa. El análisis de los datos mostró que, en el período comprendido entre 2007 y 2015, la Política socioeducativa de Paraná presentó una lógica centralizada, cada vez más, en las intervenciones dirigidas al individuo en detrimento de las acciones colectivas. Con los cambios en el lugar institucional del Sistema de Atención Socioeducativa, hubo cambios en las características y la asignación de fondos de los programas existentes, lo que sugiere la discontinuidad de los programas desarrollados a la población de adolescentes que cometieron una infracción, lo que indica la adopción de políticas gubernamentales, no efectivamente una política de Estado.

Palabras clave: socioeducación. Adolescente en conflicto con la ley. Politica social Paraná.

\section{Introdução}

Toda conduta praticada por adolescente análoga a crime ou a contravenção penal é denominada ato infracional, sendo que a esses adolescentes é destinada à Política de Socioeducação. De acordo com o Panorama Nacional da Execução das Medidas Socioeducativas de Internação, elaborado pelo Conselho Nacional de Justiça (CNJ, 2012), os atos infracionais que mais correspondem à internação socioeducativa são os contra o patrimônio - como o furto e o roubo -, apesar de os atos infracionais mais gravosos e com maior repercussão midiática serem os análogos ao crime de homicídios na maioria das regiões do país. Estes são responsáveis pela internação de $20 \%$ a $28 \%$ dos adolescentes e correspondem a 7\% do total das internações da região sudeste (CNJ, 2012, p.10).

Confirmados pela repercussão midiática, observamos que os atos infracionais cometidos por adolescente acabam por causar uma reação exacerbada nos meios de 
OLIVEIRA, R. H. D. de; FIGUEIREDO, I. M. Z. A gestão da política de socioeducação no Estado do Paraná: repercussões no período de 2007 a 2015

comunicação social, nos quais, na maioria das vezes, o consenso disseminado é de uma imagem perigosa do jovem, cuja exclusão do convívio social é justificada diante da ameaça representada (REIS, 2012).

Por serem identificados como a personificação da violência, os jovens pobres têm sido sistematicamente impedidos de usufruir de direitos como a educação, a cultura e o lazer, além de terem acesso limitado a determinados, restando-lhes os espaços periféricos (PEREIRA, 2016). Logo, nem o acesso aos direitos fundamentais é garantido, o que é exemplificado no relatório do CNJ (2012), o qual indica que 8\% dos adolescentes internados em unidades socioeducativas não são alfabetizados, sendo que na região Nordeste o índice de analfabetos chega a 20\%. Considerando a matrícula e frequência escolar anterior a apreensão, 57\% dos jovens da pesquisa declararam que não frequentavam a escola, sendo o Ensino Fundamental a fase de ensino de rompimento com a escolarização da maioria deles (CNJ, 2012, p. 16).

De acordo com os dados do estado do Paraná apresentados pelo Departamento de Atendimento Socioeducativo (DEASE), em 2015, os adolescentes em cumprimento de medida socioeducativa de privação e restrição de liberdade eram predominantemente homens(93\%) sendo47\% de etnia parda em detrimento das demais autodeclarações: 37\% branca; $12 \%$ negra; menos de 1\% indígena; e demais não declaradas.

Considerando a idade dos adolescentes, 35\% tinha 17 anos; 26\%, 16 anos, e 17\%, 18 anos. Maiores de 18 anos somavam aproximadamente $2 \%$ do total. Quando analisados os atos infracionais aos quais os adolescentes estavam respondendo, o roubo era ato mais recorrente (37\%), somando-se a forma simples e agravada. 0 tráfico de drogas representava 16\% dos atos infracionais e a prática de homicídio simples e qualificado somava $15 \%$. Ademais, furtos simples e qualificados somavam $5 \%$, e o descumprimento de medida socioeducativa anteriormente imposta representava aproximadamente $3 \%$. Quando analisada a renda familiar, 52\% das famílias ganhava de 1 a 2 salários mínimos. A composição familiar de 4 a 6 pessoas representava 52\%. (DEASE, 2015, p. 25-26).

Existindo a falta de condições mínimas de dignidade na escola, no trabalho e na saúde, dentre outros locais, podemos entender, como violador primordial, o Estado, instituição criada com a função de intermediar as relações entre as diferentes classes, porém que mantém, em suas práticas, a desigualdade de condições existentes. Nesse processo, ocorre a violência que, no capitalismo, constitui uma das formas de exploração do homem pelo próprio homem. Saviani (2013) enfatiza que a exploração surge “[...] como 
OLIVEIRA, R. H. D. de; FIGUEIREDO, I. M. Z. A gestão da política de socioeducação no Estado do Paraná: repercussões no período de 2007 a 2015

garantia da classe dominante assegurando sua posição por meios não coercitivos tendo, porém, como razão última, a transformação da violência potencial em violência efetiva." (SAVIANI, 2013, p. 39).

Logo, os atos de violência e infração na sociedade, alicerçados nas relações sociais de produção e exploração baseadas na acumulação de capital, excluem uma parcela da população do acesso a bens produzidos socialmente, limitando-a ao exercício do papel a ela imposto pelo estigma criado e mantido socialmente. Como descrito por Michel Misse (2008) ao apresentar o conceito de "Sujeição Criminal": uma "[...] fusão plena do evento com seu autor, ainda que esse evento seja apenas potencial e que efetivamente não tenha se realizado." (MISSE, 2008, p. 380). Ou seja, a suposição de um "tipo social” propenso a cometer um crime. Nesse sentido, a relação entre a juventude pobre e a prática de ato infracional não deve ser vista como natural (BORBA; PEREIRA, 2016).

Para atender às situações de prática de infrações por adolescentes, as diferentes mediações/intervenções do Estado são descritas com a justificativa de orientar, educar ou reeducar os adolescentes. Porém, é preciso enfatizar que as motivações para práticas infracionais não devem ser depositadas exclusivamente no sujeito sem que sejam consideradas as relações sociais existentes (FEITOSA, 2011; COSSETIN, 2012; REIS, 2012; TABORDA, 2015).

Os ordenamentos jurídicos brasileiros utilizados como referência ao atendimento brasileiro ao adolescente autor de ato infracional são o Estatuto da Criança e do Adolescente (ECA), publicizado através da Lei no 8.069, de 13 de julho de 1990 e o Sistema Nacional de Atendimento Socioeducativo (SINASE), implantado através da Lei no 12.594 de 18 de janeiro de 2012 (BRASIL, 1990; 2012).

O ECA (1990) determina que, se for comprovada a conduta ilegal praticada pelo adolescente, ele deverá ser julgado, podendo chegar a cumprir uma das Medidas Socioeducativas que são compostas das mais leves às mais gravosas, como: Advertência, Obrigação de reparar o dano, Prestação de Serviço à Comunidade (PSC), Liberdade Assistida (LA), Semiliberdade, e Internação. Para a aplicação de uma das Medidas Socioeducativas, deve-se levar em conta a capacidade do adolescente para o seu cumprimento, as circunstâncias e a gravidade da infração (BRASIL, 1990). Com o intuito de regulamentar a execução destas medidas, assim como ordenar os princípios, as regras e os critérios que envolvem a execução, elaborou-se então o SINASE (2012). 
OLIVEIRA, R. H. D. de; FIGUEIREDO, I. M. Z. A gestão da política de socioeducação no Estado do Paraná: repercussões no período de 2007 a 2015

Destacamos que 22 anos separam a proposição do atendimento à população de adolescentes autores de ato infracional, em 1990, da criação, em 2012, do Sistema Nacional de Atendimento Socioeducativo (SINASE). Neste intermédio de tempo, para exemplificar, diversas foram as propostas para a alteração do ECA, sendo a maioria delas visando ao aumento da característica punitiva da Medida Socioeducativa. A primeira Proposta de Emenda Constitucional (PEC) referente à redução da maioridade penal foi apresentada na Câmara dos Deputados por Benedito Domingos, em 1993, três anos após a promulgação do ECA (1990) e 19 anos antes da organização do SINASE (2012). Conhecida como PEC 171/1993, visava à alteração da redação do Art. 228 da Constituição Federal sobre a imputabilidade penal do maior de dezesseis anos, prevendo então a redução da maioridade penal (NOBRE, 2015a, s/p). Esta, assim como diversas outras alterações previstas para o ECA que contemplavam desde a mudança da idade penal em casos específicos até o aumento do tempo de internação, dependendo do ato infracional praticado (NOBRE, 2015b, s/p), ainda não foi aprovada, porém ganha cada vez mais espaço nas discussões sobre a política de atendimento aos adolescentes em conflito com a lei.

Com essas propostas que visaram a alterar o ECA (1990) e o SINASE (2012), evidencia-se a complexidade que envolve a temática em tela, ou seja, o enrijecimento em relação às sanções impostas aos adolescentes, com maior ênfase punitiva em detrimento do caráter pedagógico.

\section{0 percurso da pesquisa}

Considerando que quanto mais entendermos sobre como se organizam e como são efetivadas as bases sociais e legais que sustentam o Sistema de Atendimento Socioeducativo, mais possibilidades de intervenção em relação àexecução da Política de Socioeducação serão empregáveis, esta pesquisa objetivou compreender como se deu a gestão da Política de Socioeducação do Estado do Paraná considerando a reorganização do atendimento aos adolescentes em conflito com a lei, no período de 2007 a 2015.

É importante ressaltarmos que por meio da Resolução no 119 do Conselho Nacional dos Direitos da Criança e do Adolescente - Conanda, em 11 de dezembro de 2006, foi criado o Sistema Nacional de Atendimento Socioeducativo - SINASE, apesar de sua promulgação ter sido efetivada em 2012. Mesmo tendo caráter de resolução, o 
OLIVEIRA, R. H. D. de; FIGUEIREDO, I. M. Z. A gestão da política de socioeducação no Estado do Paraná: repercussões no período de 2007 a 2015

documento já apresentava princípios estabelecidos para o atendimento aos adolescentes no cumprimento de Medida Socioeducativa.

No estado do Paraná, o Sistema Estadual de Atendimento Socioeducativo já esteve vinculado a diferentes secretarias de estado, sendo que a organização desse Sistema foi influenciada por diversos fatores sociais, econômicos, políticos e ideológicos. Em 2007, tinha como locus institucional o Instituto de Ação Social do Paraná (IASP), autarquia vinculada à Secretaria de Estado da Criança e Assuntos da Família (SECr). Nesse ano houve uma reorganização estadual em relação ao locus do Sistema Estadual de Atendimento Socioeducativo, passando então a fazer parte da Secretaria de Estado da Criança e Juventude (SECJ). Em 2010, este Sistema passa a ser vinculado à Secretaria de Estado da Família e Desenvolvimento Social (SEDS) e, em 2015, à Secretaria de Estado da Justiça, Cidadania e Direitos Humanos (SEJU).

A alteração do locus a que o sistema está vinculado sugere a descontinuidade das propostas anteriormente iniciadas, indicando a adoção de Políticas de Governo, e não efetivamente de uma Política de Estado. Essas mudanças também podem carregar novas percepções e aspectos de acordo com o novo locus em que o Sistema se instala, promovendo não apenas alterações na organização administrativa, mas também na gestão pública dessa Política específica.

A formulação de programas do Estado para atender às medidas determinadas pela agenda política interna é concebida como Política de Governo. Os programas que passaram por diferentes instâncias de discussão, resultando em mudanças estruturais com foco na garantia efetiva e contínua à população, independente de gestão e gestores específicos, caracterizam Políticas de Estado (OLIVEIRA, 2011). Nesse sentido, a gestão de políticas voltadas para o atendimento aos adolescentes autores de ato infracional constitui uma resposta histórica a como a sociedade está organizada e às demandas que procura responder.

Como processo de pesquisa, estipulamos a análise documental e bibliográfica. Utilizamos a metodologia de análise de conteúdo, que pode ser entendida como “[...] uma técnica de investigação que tem por finalidade a descrição objectiva [sic], sistemática e quantitativa do conteúdo manifesto da comunicação." (BERELSON³ , apud BARDIN, 1977 p. 31).

\footnotetext{
${ }^{3}$ BERELSON, B.; LAZARFELD, P. F., The analysis of communications content, University of Chicago and Columbia University, Preliminary Draft, Chicago e Nova Iorque, 1948.
} 
OLIVEIRA, R. H. D. de; FIGUEIREDO, I. M. Z. A gestão da política de socioeducação no Estado do Paraná: repercussões no período de 2007 a 2015

Como fontes primárias, foram selecionadas as legislações paranaenses acerca da transição do Sistema de Atendimento Socioeducativo no período delimitado, assim como documentos disponíveis nos sites das secretarias ainda existentes, a saber: Secretaria de Estado da Família e Desenvolvimento Social (SEDS) e Secretaria da Justiça, Trabalho e Direitos Humanos (SEJU) ${ }^{4}$. Em complemento, foram estudadas as Deliberações do Conselho Estadual dos Direitos da Criança e do Adolescente (CEDCA) e os Planos de Ação para destinação dos recursos do Fundo da Infância e Adolescência (FIA), buscando a delimitação das ações propostas pelas Secretarias. As fontes secundárias se constituíram de artigos, dissertações e teses relacionados ao tema.

\section{Conhecendo o passado}

0 atendimento aos adolescentes com envolvimento em práticas ilícitas nem sempre se deu da maneira como está organizado atualmente, sendo estruturado de acordo com as relações vivenciadas em cada época ${ }^{5}$. No estado do Paraná, existem registros do atendimento ao adolescente autor de ato infracional desde 1857, com o estabelecimento de lei para criação de instituições asilares. Em 1918 há a criação do Instituto Disciplinar, instituição que atendia jovens condenados nos termos do código penal da época. Apenas em 1925 há a criação do Juizado de Menores no Estado do Paraná, sendo o terceiro em âmbito nacional (MICALI, 2009).

A partir da promulgação nacional do Código de Menores de 1927, conhecido como Código de Mello Mattos, houve maior pressão para construção de instituições como os Abrigos e as Escolas de Preservação e de Reforma. 0 trabalho agrícola era tido como essencial na recuperação de jovens com comportamentos desajustados e, em 1933, inaugura-se a primeira das dez escolas agrícolas. A percepção da época, a qual tem reflexos até hoje, era a de que o sujeito infrator necessitava ser retirado do convívio social para uma readequação realizada por meio de tratamento médico acompanhado de medidas jurídicas (MICALI, 2009).

\footnotetext{
${ }^{4}$ Em 2015 a SEJU era denominada Secretaria de Estado da Justiça, Cidadania e Direitos Humanos. Porém, devido a legislações futuras, passa a ser denominada Secretaria de Estado da Justiça, Trabalho e Direitos Humanos.

${ }^{5}$ As terminologias foram alteradas de acordo com a época e as legislações vigentes. Assim, nesta seção, serão utilizados os termos de acordo com a época correspondente.
} 
OLIVEIRA, R. H. D. de; FIGUEIREDO, I. M. Z. A gestão da política de socioeducação no Estado do Paraná: repercussões no período de 2007 a 2015

Com o aumento da urbanização paranaense e, consequentemente, a presença de mais crianças e adolescentes abandonados e infratores, há a intensificação da intervenção do poder judiciário. Nesta época, o atendimento ao público infanto juvenil pobre, delinquente e abandonado estava vinculado à Secretaria de Justiça e devido à observação do aumento das denúncias de maus tratos sofridos pelos menores, em 1947, há uma mudança no locus deste atendimento, que passa a compor o Departamento de Assistência Social (DAS) o qual, por sua vez, estava relacionado à Secretaria da Saúde e da Assistência Social (MICALI, 2009).

Em 1961, após um levantamento geral da situação do atendimento ao adolescente infrator no estado do Paraná que evidenciou a situação periclitante vivenciada nas unidades existentes, cria-se o Instituto de Assistência ao Menor (IAM), subordinado à Secretaria de Estado de Trabalho e Assistência Social, o qual tinha como responsabilidade formular e executar a política governamental de assistência ao menor. Após o Golpe Militar de 1964, nacionalmente houve a criação da Fundação Nacional do Bem Estar do Menor (FUNABEM), que passou a ser a responsável pela reorganização da política voltada ao público infanto-juvenil, realizada através da criação das Fundações Estaduais de Bem Estar do Menor (FEBEMs). 0 estado do Paraná optou por não utilizar a nomenclatura apresentada pela esfera federal, apesar de as instituições construídas e mantidas pelo estado se alinharem às diretrizes nacionais (MICALI, 2009).

Em 1969, o atendimento paranaense ao adolescente infrator passou a fazer parte da Secretaria de Trabalho e Assistência Social e não mais esteve vinculada ao quadro da segurança pública, como anteriormente (MICALI, 2009). Cinco anos depois, em 1974, há uma nova mudança do IAM, que se desvincula da Secretaria de Estado de Trabalho e Assistência Social e passa a compor o quadro da Secretaria de Estado da Saúde e do Bem Estar Social. Em 1987, há a extinção do IAM, sendo suas atividades assumidas pela Fundação de Ação Social do Paraná (FASPAR), estando esta vinculada à Secretaria do Trabalho e Ação Social (MICALI, 2009; LOPES, 2014).

Em 1988, com a promulgação da Constituição Federal, concebida com o processo de redemocratização brasileira e, em 1990, com a promulgação do Estatuto da Criança e do Adolescente (ECA), o poder executivo passou a readequar as intervenções direcionadas à população adolescente, principalmente no que se refere à descentralização do atendimento. 
OLIVEIRA, R. H. D. de; FIGUEIREDO, I. M. Z. A gestão da política de socioeducação no Estado do Paraná: repercussões no período de 2007 a 2015

Assim sendo, em 1991 há a criação do Conselho Estadual de Direitos da Criança e do Adolescente (CEDCA), sendo este o "[...] órgão consultivo, deliberativo e controlador da política de atendimento à infância e juventude, vinculado à secretaria de Estado responsável pela execução da política estadual de atendimento à criança e ao adolescente." (PARANÁ, 1991, s/p). Em 1995, há a extinção da FASPAR e a criação do Instituto de Ação Social do Paraná (IASP), uma autarquia vinculada à Secretaria de Estado da Criança e Assuntos da Família (SECr) (MICALI, 2009; LOPES, 2014).

No ano de 2003, o IASP vincula-se à Secretaria de Estado do Emprego, Trabalho e Promoção Social (SETP), que teve como objetivo coordenar e executar a Política de Assistência Social estadual (LOPES, 2014), sendo que a partir de então o IASP teve delimitado o seu foco exclusivamente aos adolescentes em conflito com a lei.

Repensar sobre o Sistema de Atendimento Socioeducativo teve como uma das motivações a ocorrência de uma rebelião no Educandário São Francisco no dia 23 de setembro de 2004 (MICALI, 2009; LOPES, 2014; COSSETIN, 2012). Na ocasião, sete adolescentes foram mortos. Sendo estes provenientes de diferentes cidades, impulsionou-se a discussão acerca da descentralização do atendimento, sendo necessária a inauguração de unidades de atendimento no interior do estado, assim como a construção de uma proposta pedagógica apropriada a cada modalidade de Medida Socioeducativa.

A sistematização das ações pensadas para o atendimento socioeducativo se concretizou em 2006 por meio da elaboração dos "Cadernos do IASP" 6 , sendo o conjunto de documentos considerado como base para a organização do atendimento nas novas unidades (LOPES, 2014).

\section{A transição do sistema de atendimento socioeducativo paranaense entre 2007 e 2015}

No Paraná, com a reorganização das ações voltadas aos adolescentes em conflito com a lei, a descentralização das ações para o interior do estado e a construção de novas unidades, o Sistema Estadual de Atendimento Socioeducativo adquiriu uma nova estrutura e nova dimensão.

\footnotetext{
${ }^{6}$ Conjunto de produções, compreendendo os seguintes volumes: 1- Gerenciamento de Crise; 2- Rotinas de Segurança; 3- Compreendendo o Adolescente; 4- Gestão de Centro de Socioeducação; 5- Práticas de Socioeducação.
} 
OLIVEIRA, R. H. D. de; FIGUEIREDO, I. M. Z. A gestão da política de socioeducação no Estado do Paraná: repercussões no período de 2007 a 2015

Isso ocorreu tendo como uma das consequências o aumento da quantidade de vagas para o atendimento aos adolescentes no Sistema Estadual de Atendimento Socioeducativo no período de 2003 a 2015 como se pode constatar na Tabela 1.

Tabela 1. Quantidade de vagas no Sistema Estadual de Atendimento Socioeducativo Paranaense (2003 - 2015)

\begin{tabular}{lcccc}
\hline & 2003 & 2010 & 2014 & 2015 \\
\hline $\begin{array}{l}\text { Internação } \\
\text { Provisória }\end{array}$ & 466 & 1131 & 936 & 339 \\
\cline { 1 - 4 } Internação & & & & 560 \\
\hline Semiliberdade & 54 & 104 & 116 & 113 \\
\hline TOTAL & $\mathbf{5 2 0}$ & $\mathbf{1 2 3 5}$ & $\mathbf{1 0 5 2}$ & $\mathbf{1 0 3 2}$ \\
\hline
\end{tabular}

Fonte: SECJ (2010); SEDS (2014); SEJU (2015); DEASE (2015).

É pertinente observar que a quantidade de vagas para o atendimento aos adolescentes no Sistema Estadual de Atendimento Socioeducativo paranaense, no período de 2003 a 2015, foi significativa se tratando da Medida Socioeducativa de Internação em decorrência da Internação Provisória, como apresentado na Tabela 2.

Tabela 2. Quantidade de Internações Provisórias e Internações no estado do Paraná (2003 - 2015)

\begin{tabular}{|c|c|c|c|c|c|c|c|c|c|c|c|c|c|}
\hline & $\begin{array}{l}200 \\
3\end{array}$ & $\begin{array}{l}200 \\
4\end{array}$ & $\begin{array}{l}200 \\
5\end{array}$ & $\begin{array}{l}200 \\
6\end{array}$ & 2007 & $\begin{array}{l}200 \\
8\end{array}$ & $\begin{array}{l}200 \\
9\end{array}$ & $\begin{array}{l}201 \\
0\end{array}$ & 2011 & $\begin{array}{l}201 \\
2\end{array}$ & 2013 & $2014^{7}$ & $\begin{array}{l}201 \\
5\end{array}$ \\
\hline $\begin{array}{l}\text { Internação } \\
\text { Provisória }\end{array}$ & $\begin{array}{l}116 \\
4\end{array}$ & $\begin{array}{l}212 \\
3\end{array}$ & $\begin{array}{l}223 \\
8\end{array}$ & $\begin{array}{l}256 \\
6\end{array}$ & 2436 & $\begin{array}{l}293 \\
5\end{array}$ & $\begin{array}{l}311 \\
9\end{array}$ & $\begin{array}{l}323 \\
6\end{array}$ & 2873 & $\begin{array}{l}287 \\
3\end{array}$ & 2916 & $\approx 2250$ & $\begin{array}{l}211 \\
4\end{array}$ \\
\hline Internação & 424 & 933 & 675 & 804 & 1348 & $\begin{array}{l}162 \\
0\end{array}$ & $\begin{array}{l}171 \\
0\end{array}$ & $\begin{array}{l}204 \\
9\end{array}$ & 1897 & $\begin{array}{l}187 \\
7\end{array}$ & 1912 & $\approx 2000$ & $\begin{array}{l}176 \\
6\end{array}$ \\
\hline
\end{tabular}

Relação entre

$\begin{array}{llllllllllllll}\text { Internação e } & 36 \% & 43 \% & 30 \% & 31 \% & 55 \% & 55 \% & 55 \% & 63 \% & 66 \% & 65 \% & 65 \% & \approx 88 \% & 83 \%\end{array}$ Internação provisória

Fonte: SECJ (2010); SEDS (2014); SEJU (2015); DEASE (2015).

\footnotetext{
${ }^{7}$ Apesar de existir um documento publicado pela SEJU no ano de 2015, denominado Plano Estadual de Atendimento Socioeducativo, os dados referentes à Internação e à Internação Provisória, no ano de 2014, não são explicitados com precisão. Os valores representados nesta tabela referentes ao ano de 2014 são aproximados considerando a análise dos gráficos apresentados no documento da SEJU (2015).
} 
OLIVEIRA, R. H. D. de; FIGUEIREDO, I. M. Z. A gestão da política de socioeducação no Estado do Paraná: repercussões no período de 2007 a 2015

Analisando a Tabela 2 pode-se constatar que, em 2003, a Medida de Internação representou um percentual de 36\% dos adolescentes que passavam pela Internação Provisória. Em 2004, há um aumento, porém nos dois anos seguintes há uma diminuição deste percentual. Em 2007, este índice passou para 55\% dos casos, mantendo-se nesta média até o ano de 2009, sendo que ,em 2010, há um novo aumento significativo, totalizando 60\%. No período de 2010 a 2013, os dados referentes à Internação e à Internação Provisória apresentaram pouca variação. Nos anos de 2014 e 2015, observase novamente um salto significativo na porcentagem de adolescentes que são sentenciados ao cumprimento da Medida de Internação Socioeducativa, sendo que ,em 2015, totalizam 83\% dos casos. Situações como a abertura de novas unidades e a interdição de vaga por situações adversas influenciam na aplicação de medidas de internação quando da internação provisória.

O constante aumento na quantidade de internações indica que cada vez mais o judiciário tem buscado a Medida Socioeducativa de Internação como forma de intervir nas situações de infração, apontando tendências higienistas ainda na atualidade (FEITOSA, 2011). A proposta difundida de privilegiar o atendimento comunitário no território do adolescente com foco na manutenção e fortalecimento dos vínculos familiares e comunitários é contrariada pela prática da institucionalização, mesmo que esta prática tenha sido comprovada como ineficaz historicamente. A partir desta percepção, Feitosa (2011) confirma que, resguardadas as devidas diferenças tempo-espaciais, as sentenças judiciárias permanecem carregadas de aspectos do ideário higienista e da doutrina vinculada ao Código de Menores.

É importante ressaltar que o contexto em que a condução da política da criança e do adolescente no estado do Paraná está alicerçada é complexo, sendo as relações permeadas por disputas constantes, seja entre partidos, serviços, instituições ou até mesmo disputas pessoais (LOPES, 2014).

A reestruturação do Sistema de Atendimento Socioeducativo paranaense iniciada em 2006 tem continuidade com a criação da Secretaria de Estado da Criança e da Juventude (SECJ), sendo que na década seguinte o Sistema de Atendimento Socioeducativo estadual paranaense teve seu locus institucional alterado mais de duas vezes, como apresentado no Quadro 1.

Quadro 1. Leis e respectivos artigos referentes às alterações do locus do Sistema de Atendimento Socioeducativo Paranaense (2007 - 2014) 
OLIVEIRA, R. H. D. de; FIGUEIREDO, I. M. Z. A gestão da política de socioeducação no Estado do Paraná: repercussões no período de 2007 a 2015

\begin{tabular}{|l|l|}
\hline \multicolumn{1}{|c|}{ Leis } & \multicolumn{1}{|c|}{ Artigos referentes à alteração do locus do Sistema Socioeducativo } \\
\hline $\begin{array}{l}\text { Lei no 15.604, de 15 } \\
\text { de agosto de 2007 }\end{array}$ & $\begin{array}{l}\text { Art. 2o. Fica extinto o Instituto de Ação Social do Paraná - IASP, criado } \\
\text { pela Lei no 8.485, de 03 de junho de 1987, transformado em Autarquia } \\
\text { pela Lei no 9.663, de 16 de julho de 1991, ficando suas atribuições, } \\
\text { servidores, cargos, saldo das dotações orçamentárias, créditos, receitas } \\
\text { e patrimônio, transferidos ao âmbito administrativo da Secretaria de } \\
\text { Estado da Criança e da Juventude - SECJ. }\end{array}$ \\
\hline $\begin{array}{l}\text { Lei no 16.840, de 28 } \\
\text { de junho de 2011 }\end{array}$ & $\begin{array}{l}\text { Art. 10 A Secretaria de Estado da Criança e da Juventude - SECJ, a que } \\
\text { se refere o Art. 1o da Lei no 15.604, de 15 de agosto de 2007, fica } \\
\text { transformada em Secretaria de Estado da Família e Desenvolvimento } \\
\text { Social - SEDS, tendo por finalidade as atividades concernentes à } \\
\text { organização, à promoção, ao desenvolvimento e à coordenação: } \\
\text { III - do Sistema de Atendimento Socioeducativo }\end{array}$ \\
\hline $\begin{array}{l}\text { Lei no 18.374, de 15 } \\
\text { de dezembro de } \\
2014\end{array}$ & $\begin{array}{l}\text { Art. 14. Transfere da Secretaria de Estado do Trabalho e } \\
\text { Desenvolvimento Social - SEDS para o âmbito de ação da Secretaria de } \\
\text { Estado da Justiça, Cidadania e Direitos Humanos - SEJU as atribuições } \\
\text { de organização, promoção, desenvolvimento e coordenação do Sistema } \\
\text { de Atendimento Socioeducativo. } \\
\text { § 10 Os Centros de Socioeducação - CENSE passam a integrar a } \\
\text { estrutura organizacional da Secretaria de Estado da Justiça, Cidadania } \\
\text { e Direitos Humanos - SEJU. }\end{array}$ \\
\hline
\end{tabular}

Fonte: Paraná $(2007 ; 2011 ; 2014)$.

Com a criação da SECJ, em 2007, houve a concepção de programas não somente direcionados aos adolescentes autores de ato infracional, mas também para os que se encontravam em situação de vulnerabilidade social. Tais ações teriam como foco a construção de uma "Política Estadual para Garantia de Direitos Humanos Fundamentais de Criança e Juventude, fundada na intersetorialidade como previsto no ECA - 1990" (LOPES, 2014, p. 116). Ficou evidenciado nesse período o interesse da gestão pública em estruturar uma rede de atendimento anteriormente fragilizada, sendo que grande parte das ações da Secretaria eram direcionadas ao atendimento aos adolescentes em conflito com a lei e a Política de Socioeducação, apesar de também fazerem parte da pasta outras esferas de atendimento.

Todavia, não se pode dizer que estas novas ações se estruturaram enquanto Políticas de Estado, visto que historicamente não se consolidaram. Mesmo com ações que estavam direcionadas numa perspectiva intersetorial baseada na intervenção comunitária, o que foi consolidado foram as novas unidades de internação, fortalecendo a lógica do encarceramento.

No decorrer da gestão da SECJ, que compreendeu os anos de 2007 a 2010, foram difundidos três instrumentos que embasaram as ações pedagógicas realizadas no interior 
OLIVEIRA, R. H. D. de; FIGUEIREDO, I. M. Z. A gestão da política de socioeducação no Estado do Paraná: repercussões no período de 2007 a 2015

das Unidades de Atendimento. O primeiro, denominado de Estudo de Caso, favoreceu a troca de informações entre os setores e as decisões e os encaminhamentos referentes ao caso passaram a ser tomadas coletivamente. 0 segundo instrumento é denominado Conselho Disciplinar e instituiu-se como espaço de julgamento frente às faltas disciplinares cometidas pelos adolescentes. 0 terceiro instrumento apresentado pela SECJ é o Plano Personalizado de Atendimento (PPA) que, apesar de ser apresentado como um Projeto de Vida feito pelo e para o adolescente, teve a característica de ser um "prêmio" usualmente relacionado ao bom comportamento. Dos três instrumentos apresentados, apenas o PPA não é mais tido como referência às práticas socioeducativas, tendo sido substituído pelo Plano Individualizado de Atendimento (PIA), instrumento de previsão, registro e gestão das atividades desenvolvidas com o adolescente durante o cumprimento da Medida Socioeducativa previsto no SINASE.

Na gestão SECJ foram criados os programas de acompanhamento de adolescentes, o quais tiveram como atributo fortalecer a rede de atendimento ao adolescente em conflito com a lei através da criação de espaços destinados à cultura e ao lazer, além do cofinanciamento de programas de cumprimento de Medida Socioeducativa em Meio Aberto e de proteção a ameaçados de morte.

É importante observarmos que estes programas foram efetivados por meio da utilização dos recursos do Fundo Estadual para a Infância e Adolescência (FIA) e não a partir de receitas próprias do estado, estando passíveis de suspensão ao encerrar o plano de aplicação específico, homologado mediante deliberação do Conselho Estadual de Direitos da Criança e do Adolescente (CEDCA) (PARANÁ, 1991, s/p).

O CEDCA é entendido como o "[...] órgão consultivo, deliberativo e controlador da política de atendimento à infância e juventude, vinculado à secretaria de Estado responsável pela execução da política estadual de atendimento à criança e ao adolescente." (PARANÁ, 1991, s/p). Porém, apesar da finalidade de representação social, se vinculado à esfera estatal, há a diminuição da possibilidade de participação da sociedade civil. Assim, ao mesmo tempo em que o Estado compartilha as suas responsabilidades com a sociedade civil, utiliza este espaço para legitimar as suas ações.

Na gestão da SECJ o orçamento ficou restrito para a ação na área de socioeducação em detrimento das demais áreas do sistema de garantia de direitos (LOPES, 2014).

Em decorrência da alteração do governo estadual, após processo eleitoral, com a justificativa de exprimir uma nova abordagem de enfrentamento aos problemas 
OLIVEIRA, R. H. D. de; FIGUEIREDO, I. M. Z. A gestão da política de socioeducação no Estado do Paraná: repercussões no período de 2007 a 2015

existentes no âmbito estadual, em 2011 a nova gestão do governo do estado paranaense realizou alterações na pasta em que o Sistema de Atendimento Socioeducativo estava inserido. Tal pasta passou a ser denominada Secretaria de Estado da Família e do Desenvolvimento Social (SEDS), através da Lei no 16.840, de 28 de Junho de 2011.

Juntamente com a alteração do locus institucional do Sistema de Atendimento Socioeducativo, foram observadas também estratégias de ações que objetivaram imprimir na Política voltada à população juvenil as características deste novo período de gestão. Em relação ao atendimento específico aos adolescentes em conflito com a lei, foi constatada a descontinuidade de programas anteriormente considerados como essenciais, assim como o início de novas intervenções e a priorização de ações na área da assistência social com foco no atendimento às famílias dos adolescentes.

Na nova gestão, a tendência foi a de contratação de empresas específicas para a realização de atividades culturais, esportivas e de qualificação profissional básica, terceirizando os serviços que antes eram realizados pelos próprios servidores das Unidades de Atendimento.

A falta de uma Política de Estado efetiva na área da infância e da adolescência, o que ocorreu anteriormente, teve como resultado a reorganização de acordo com os interesses que não os específicos a área. Essa discussão já havia sido deflagrada pelo Centro de Apoio Operacional das Promotorias da Criança e do Adolescente (CAOPCAE) quando, no ano de 2011, a proposta de atendimento aos adolescentes em conflito com a lei foi realizada pelo órgão encarregado de gerir o Sistema Penitenciário.

Para o CAOPCAE (2011), este sistema apresentava uma “[...] concepção e prática absolutamente incompatíveis com as normas e princípios que regem a matéria, o que fatalmente resultará em enorme prejuízo à adequação e eficácia das intervenções estatais a serem realizadas." (CAOPCAE, 2011, p. 2). Com a mudança no locus, deflagra-se também a fragilidade do Sistema de Garantia de Direito das Crianças e Adolescentes, assim como do Conselho Estadual de Direitos da Criança e do Adolescente (CEDCA), visto que este é o órgão que "[...] detém a competência e a prerrogativa de formular tal política pública, bem como de controlar sua execução por parte do Poder Público em âmbito estadual exercendo o chamado 'controle social' sobre os atos do governo." (CAOPCAE, 2011, p. 3, grifos no original).

Mesmo com estas discussões já realizadas, em 2014, a mudança de locus do Sistema de Atendimento Socioeducativo da SEDS para a SEJU aconteceu devido a 
OLIVEIRA, R. H. D. de; FIGUEIREDO, I. M. Z. A gestão da política de socioeducação no Estado do Paraná: repercussões no período de 2007 a 2015

diferentes fatores não diretamente ligados ao Sistema de Atendimento Socioeducativo, mas também não totalmente alheios à visão de atendimento aos adolescentes em conflito com a lei. È importante recobrar que em 2013 e em 2014 o Sistema Prisional Paranaense passou a registrar uma série de motins e rebeliões nas penitenciárias, presídios e cadeias do estado (BATISTA, 2014, s/p), o que levou o poder executivo a reorganizar o Departamento de Execução Penal, que passou a ser vinculando à Secretaria Estadual de Segurança Pública (SESP) em 2015. No mesmo período há a transferência do Sistema de Atendimento Socioeducativo da SEDS para o âmbito de ação da Secretaria de Estado da Justiça, Cidadania e Direitos Humanos (SEJU). Com a mudança, na prática, o Sistema Socioeducativo preencheu o espaço que o departamento penitenciário ocupara, com repercussões no atendimento proposto.

Ao ser incorporado pela SEJU, o Sistema Estadual de Atendimento Socioeducativo assumiu algumas características já existentes naquela Secretaria. Houve uma maior atenção às questões organizacionais, sendo que os procedimentos existentes anteriormente no departamento penitenciário, não mais pertencente à SEJU, passaram a constituir referência para o Departamento de Atendimento Socioeducativo.

A proposição de que o Estado deveria apresentar uma característica mais punitiva frente às situações adversas infracionais foi essencial para a alteração no locus institucional do Sistema de Atendimento Socioeducativo. Pastana (2009, p. 2) defende que o nosso projeto político "[...] rejeita o Estado em sua função interventora no campo econômico e social, porém projeta na gestão pública a responsabilidade por controlar, ainda que de forma autoritária, todos os transtornos sociais advindos desse projeto, como, por exemplo, o aumento da criminalidade." (PASTANA, 2009, p. 2). Ou seja, minimiza-se a ação do Estado em políticas de fortalecimento social, e exige-se uma ação enérgica em situações decorrentes desta diminuição.

Para visibilidade dos programas paranaenses das gestões do Sistema de Atendimento Socioeducativo da SECJ, SEDS e SEJU, apresentamos o Quadro 02, que compreende o período de 2007 a 2015 :

Quadro 2. Programas das gestões SECJ, SEDS e SEJU do estado do Paraná (2007 - 2015)

\begin{tabular}{|c|c|c|c|c|c|c|c|c|c|}
\hline SECRETARIAS & \multicolumn{4}{|c|}{ SECJ } & \multicolumn{4}{c|}{ SEDS } & SEJU \\
\hline PROGRAMAS & 2007 & 2008 & 2009 & 2010 & 2011 & 2012 & 2013 & 2014 & 2015 \\
\hline $\begin{array}{c}\text { Liberdade Cidadã - Liberação de } \\
\text { recursos ao atendimento direto ao }\end{array}$ & $\mathrm{x}$ & - & $\mathrm{x}$ & $\mathrm{x}$ & $\mathrm{x}$ & $\mathrm{x}$ & $\mathrm{x}$ & $\mathrm{x}$ & $\mathrm{x}$ \\
\hline
\end{tabular}


OLIVEIRA, R. H. D. de; FIGUEIREDO, I. M. Z. A gestão da política de socioeducação no Estado do Paraná: repercussões no período de 2007 a 2015

\begin{tabular}{|c|c|c|c|c|c|c|c|c|c|}
\hline $\begin{array}{c}\text { adolescente em conflito com a lei em } \\
\text { meio aberto } \\
\end{array}$ & & & & & & & & & \\
\hline $\begin{array}{c}\text { Programa Atitude - Serviços básicos } \\
\text { com foco na prevenção ao } \\
\text { envolvimento com ilícitos, por meio } \\
\text { de articulação em rede e da } \\
\text { intersetorialidade } \\
\end{array}$ & $\mathrm{x}$ & $\mathrm{x}$ & $\mathrm{x}$ & $\mathrm{x}$ & $\mathrm{x}$ & - & - & - & - \\
\hline \begin{tabular}{|c|} 
Centros da Juventude - Atividades \\
que possibilitem a adolescentes e a \\
jovens produzirem e acessarem bens \\
culturais e artísticos, participarem de \\
atividades esportivas e tecnológicas \\
\end{tabular} & - & - & $\mathrm{x}$ & $x$ & $x$ & $\mathrm{x}$ & $\mathrm{x}$ & $x$ & $\mathrm{x}$ \\
\hline \begin{tabular}{|c|}
$\begin{array}{c}\text { Bolsa Egresso - Pagamento de bolsa a } \\
\text { adolescentes egressos do Sistema } \\
\text { Socioeducativo }\end{array}$ \\
\end{tabular} & $x$ & $x$ & $x$ & $x$ & $x$ & $\mathrm{x}$ & - & - & - \\
\hline \begin{tabular}{|c|} 
PPCAAM - Proteção especial a \\
crianças e adolescentes ameaçados \\
de morte ou em risco de serem \\
vítimas de homicídio \\
\end{tabular} & - & $\mathrm{x}$ & $\mathrm{x}$ & $x$ & $\mathrm{x}$ & $x$ & - & - & - \\
\hline \begin{tabular}{|c|} 
AFAI - Repasse de recursos aos \\
municípios que apresentam um \\
Plano de Ação Intersetorial para o \\
atendimento às famílias dos \\
adolescentes que cumprem a Medida \\
Socioeducativa no Cense \\
\end{tabular} & - & - & - & - & - & $\mathrm{x}$ & $\mathrm{x}$ & $\mathrm{x}$ & $\mathrm{x}$ \\
\hline \begin{tabular}{|c|} 
Projeto Aproximando Famílias - \\
Custeio mensal do deslocamento dos \\
familiares até as Unidades de \\
Atendimento \\
\end{tabular} & - & - & - & - & - & - & $\mathrm{x}$ & $\mathrm{x}$ & $\mathrm{x}$ \\
\hline $\begin{array}{c}\text { Projetos de cultura, esporte e lazer - } \\
\text { (não denominados) }\end{array}$ & - & - & - & - & $\mathrm{x}$ & $\mathrm{x}$ & $\mathrm{x}$ & - & - \\
\hline \begin{tabular}{|c|} 
Qualificação Profissional - Realização \\
de cursos de qualificação por meio \\
de empresa contratada \\
\end{tabular} & - & - & - & - & - & - & $x$ & $\mathrm{x}$ & $\mathrm{x}$ \\
\hline \begin{tabular}{|c|} 
Karatê no Cense - Atividades de \\
Karatê no interior das Unidades de \\
Atendimento, de acordo com o porte \\
da Unidade \\
\end{tabular} & - & - & - & - & - & $\mathrm{x}$ & $\mathrm{x}$ & $\mathrm{x}$ & $\mathrm{X}$ \\
\hline $\begin{array}{c}\text { Projeto Culturação - Oficinas } \\
\text { culturais no interior das unidades. } \\
\text { Vinculado ao Programa Liberdade } \\
\text { Cidadã } \\
\end{array}$ & - & - & $x$ & $\mathrm{x}$ & - & - & $\mathrm{x}$ & - & - \\
\hline $\begin{array}{l}\text { Projeto Arte e Ação - Atividades de } \\
\text { esporte, cultura e lazer para } \\
\text { adolescentes em cumprimento de } \\
\text { Medida Socioeducativa }\end{array}$ & - & - & - & - & - & - & - & - & $\mathrm{x}$ \\
\hline
\end{tabular}

Fonte: CEDCA (2017); PARANÁ (2008; 2010); SECJ (2010); SEDS (2013). Elaborado pelos autores.

A análise do Quadro 2 evidencia uma determinada descontinuidade dos programas paranaenses das gestões do Sistema de Atendimento Socioeducativo da SECJ, SEDS e SEJU, 
OLIVEIRA, R. H. D. de; FIGUEIREDO, I. M. Z. A gestão da política de socioeducação no Estado do Paraná: repercussões no período de 2007 a 2015

no período de 2007 a 2015 Tal descontinuidade está relacionada, possivelmente, à redução em relação à destinação de verbas e/ou em relação às características dos programas e suas ações.

Por isso, se de acordo com os preceitos de Lopes (2014) ocorre a justicialização das Medidas Socioeducativas, mantendo-as contínuas e permanentes, podemos inferir que no período de 2007 a 2015, as gestões do Sistema de Atendimento Socioeducativo da SECJ, SEDS e SEJU foram marcadas por uma Política de Estado caracterizada pela manutenção da lógica do encarceramento dos jovens, bem como por uma Política de Governo quando da continuidade dos programas específicos em períodos delimitados. Logo, representaram as características setoriais vinculadas a cada gestão, com programas específicos da socioeducação ou programas específicos na área da assistência social.

\section{As repercussões do Movimento da Política de Socioeducação - algumas reflexões}

Com o propósito de compreender a gestão da Política de Socioeducação do Estado do Paraná no período de 2007 a 2015 podemos afirmar que os diferentes enunciados foram utilizados como justificativas para o processo de transição dos diferentes loci, ou seja, da transição das diferentes secretarias, SECJ, SEDS e SEJU, em relação à reorganização do atendimento aos adolescentes em conflito com a lei.

Nesse caso, os enunciados sugeriram determinada instabilidade dos programas voltados ao atendimento dos adolescentes em conflito com a lei que, em sua maioria, são jovens pobres, pardos e negros e desvinculados da escola, frente a garantia dos direitos fundamentais (CNJ, 2012; DEASE, 2015). A não garantia destes direitos está relacionada à personificação da própria violência em que estão inseridos.

A operacionalização das propostas nas diferentes gestões (SECJ, SEDS, SEJU) apontou para uma prática voltada à responsabilização individual dos sujeitos, desconsiderando as consequências da lógica econômica e das relações sociais de produção (FEITOSA, 2011; COSSETIN, 2012; REIS, 2012; TABORDA, 2015). Logo, o encarceramento de adolescentes, que tem sua lógica questionada, continua sendo utilizado como mecanismo para administração das desigualdades econômico-sociais, mesmo sendo esta prática incompatível com o explícito na legislação:prioridade às ações em meio aberto, na comunidade e no território de origem dos jovens. 
OLIVEIRA, R. H. D. de; FIGUEIREDO, I. M. Z. A gestão da política de socioeducação no Estado do Paraná: repercussões no período de 2007 a 2015

Os objetivos da Política de Socioeducação, que em tese visa à responsabilização do adolescente na prática do ato infracional por meio de uma intervenção pedagógica com foco em sua integração à sociedade somada à desaprovação desta conduta delituosa, refletem a complexidade que envolve a análise da própria Política de Socioeducação, em que as práticas socioeducativas têm sido repressoras ao valorizar e priorizar a Medida Socioeducativa Internação.

Ao invés do investimento em medidas em meio aberto, liberdade assistida e prestação de serviços à comunidade e medida de semiliberdade, a internação tem sido a alternativa priorizada- conforme evidenciado com a abertura de novas unidades - quando deveria ser considerada como exceção aos casos, como prevê o SINASE.

No período de 2007 a 2015, a Política de Socioeducação paranaense apresentou uma lógica vinculada, cada vez mais, intervenções direcionadas ao indivíduo, cuja segregação confronta o que preconiza a proposta do SINASE, assim como a defendida pelo Sistema Único de Assistência Social (SUAS) e pelo Sistema Único de Saúde (SUS), cujas ações devem ser organizadas baseadas no território, atendendo as demandas e necessidades dos usuários do serviço.

A efetivação e/ou a manutenção dos programas, seja na garantia de repasse de verbas ou no investimento contínuo da formação dos profissionais que atuam no Sistema de Atendimento Socioeducativo, deve ser consolidada como uma Política de Estado. Baseado neste fazer, é primordial a interação da família, da comunidade, da sociedade em geral e do poder público, como prevê o Estatuto da Criança e do Adolescente (BRASIL, 1990), para a realização de ações que assegurem a efetivação dos direitos, ultrapassando a dimensão individual e desenvolvendo práticas que contribuam para a promoção de mudanças na vida dos adolescentes.

\section{Referências}

BARDIN, L. Análise de conteúdo. Edições 70. Lisboa - Portugal, 1977.

BATISTA, R. Em um ano, Paraná registra 18 revoltas de presos em presídios. Gazeta do Povo. Curitiba, 24 ago. 2014. Disponível em: https://www.gazetadopovo.com.br/. Acesso em: 23 jun. 2017.

BORBA, P. L. O., PEREIRA, B. P. Traçados de vida e as marcas do sistema socioeducativo. In LOPES, R. E., MALFITANO, A. P. S. (org) Terapia Ocupacional Social: desenhos teóricos e contornos práticos. São Carlos: EduFSCar, p. 331-338, 2016. 
OLIVEIRA, R. H. D. de; FIGUEIREDO, I. M. Z. A gestão da política de socioeducação no Estado do Paraná: repercussões no período de 2007 a 2015

BRASIL. Decreto-lei no 8.069. Estatuto da Criança e do Adolescente - ECA, Brasília, DF, 13 jul. 1990.

BRASIL. Lei no 12.594 . Institui o Sistema Nacional de Atendimento Socioeducativo

(Sinase), regulamenta a execução das medidas socioeducativas destinadas a adolescente que pratique ato infracional, Brasília, DF, 18 jan. 2012.

CAOPCAE, CENTRO DE APOIO OPERACIONAL À CRIANÇA E AO ADOLESCENTE,

Subsídios para o debate sobre a proposta de extinção da Secretaria de Estado da Criança e da Juventude - SECJ/PR. Curitiba-PR, 2011 Disponível em

http://www.crianca.mppr.mp.br/arquivos/File/download/manifesto_

contra_extincao.pdf. Acesso em: 15 jun. 2017.

CEDCA. Deliberações/Resoluções - Cedca/PR. Disponível em:

http://www.cedca.pr.gov.br/modules/conteudo/conteudo.php?conteudo=15. Acesso em: 16 Jun. 2018.

CNJ. CONSElHo nACIONAL DE JUSTIÇA. Pesquisa Econômica Aplicada. Panorama Nacional - A Execução das Medidas Socioeducativas de Internação. 2012. Disponível em: http://www.cnj.jus.br/images/pesquisas-

judiciarias/Publicacoes/panorama nacional doj web.pdf. Acesso em: 05 Jun 2018.

COSSETIN, M. Socioeducação no Estado do Paraná: Os sentidos de um enunciado necessário. Dissertação (Mestrado/PPGE), Universidade Estadual do Oeste do Paraná UNIOESTE, Cascavel-PR, 2012.

DEASE. Relatório de Ações do Departamento de Atendimento Socioeducativo. Paraná, 2015. Disponível em:

http://www.dease.pr.gov.br/arquivos/File/relatorio dease 2015.pdf. Acesso em: 07 jul. 2017

FEITOSA, J. B. A internação do adolescente em conflito com a lei como "única alternativa": reedição do ideário higienista 243 f. Dissertação (Mestrado em Psicologia) - do Centro de Ciências Humanas, Letras e Artes, Universidade Estadual de Maringá UEM, Maringá, 2011.

LOPES, J. E. Política da Secretaria de Estado da Criança e Juventude do Paraná no período 2007-2010: Referenciais cognitivos e normativos. 2014. 204f. Tese (Doutorado em Educação) - Universidade Federal do Paraná, Curitiba, 2014.

MICALI, J. O Dilema da Descentralização de Poder: um estudo sobre as políticas de atenção ao adolescente autor de ato infracional no Paraná. 2009. 132f. Dissertação (Mestrado em Serviço Social e Política Social) - Universidade Estadual de Londrina, Londrina, 2009.

MISSE, M. Sobre a acumulação social da violência no Rio de Janeiro. Civitas - Revista de Ciências Sociais, vol. 8, núm. 3, set/dez 2008, p. 371-385 Pontifícia Universidade Católica do Rio Grande do Sul, Porto Alegre, 2008. 
OLIVEIRA, R. H. D. de; FIGUEIREDO, I. M. Z. A gestão da política de socioeducação no Estado do Paraná: repercussões no período de 2007 a 2015

NOBRE, N. Redução da maioridade penal: o histórico de votação da proposta - Bloco 1. Reportagem Especial. Rádio Câmara. 03/08/2015. 2015a. Disponível em: http://www2.camara.leg.br/camaranoticias/radio/materias/REPORTAGEMESPECIAL/492947-REDUCAO-DA-MAIORIDADE-PENAL-O-HISTORICO-DE-VOTACAODA-PROPOSTA-BLOCO-1.html. Acesso em: 19 nov. 2017.

NOBRE. Redução da maioridade penal: propostas diferentes para o mesmo assunto Bloco 3. Reportagem Especial. Rádio Câmara. 03/08/2015. 2015b. Disponível em: http://www2.camara.leg.br/camaranoticias/radio/materias/REPORTAGEMESPECIAL/492950-REDUCAO-DA-MAIORIDADE-PENAL-PROPOSTAS-DIFERENTESPARA-0-MESMO-ASSUNTO-BLOCO-3.html. Acesso em: 19 nov. 2017.

OLIVEIRA, D. A. Das políticas de governo à política de estado: reflexões sobre a atual agenda educacional Brasileira. Educação \& Sociedade, Campinas, v. 32, n. 115, p. 323337, abr.-jun. 2011 Disponível em: www.scielo.br/pdf/es/v32n115/v32n115a05.pdf. Acesso em 02 jun 2017

PARANÁ. Decreto 3371 - 03 de Setembro de 2008. Pública o Plano Decenal dos Direitos da Criança e do Adolescente do Estado do Paraná. Curitiba (PR), 2008.

PARANÁ. Decreto 6489 - 16 de Março de 2010. Institui o Programa de Proteção a Crianças e Adolescentes Ameaçados de Morte - PPCAAM/PR, Curitiba, 2010.

PARANÁ. Lei 9579 de 22 de Março de 1991. Regulamenta o parágrafo único do artigo 216 da Constituição Estadual, que dispõe sobre a criação, organização e competência do Conselho Estadual de Defesa da Criança e do Adolescente, Curitiba, 1991.

PARANÁ. Lei 15504 de 15 de Agosto de 2007. Altera a denominação da Secretaria de Estado da Criança - SECr para Secretaria de Estado da Criança e da Juventude - SECJ, extingue o Instituto de Ação Social do Paraná - IASP e adota outras providências. Curitiba, 2007.

PARANÁ. Lei 16840 de 28 de Junho de 2011. Altera a denominação e as atribuições da Secretaria de Estado da Criança e da Juventude - SECJ; da Secretaria de Estado do Trabalho, Emprego e Promoção Social - SETP; da Secretaria de Estado da Justiça e da Cidadania - SEJU; e adota outras providências. Curitiba, 2011.

PARANÁ. Lei 18374 de 15 de Dezembro de 2014. Extingue a Secretaria de Estado do Trabalho, Emprego e Economia Solidária e transfere atribuições para a Secretaria de Estado da Família e Desenvolvimento Social, que passa a se chamar Secretaria de Estado do Trabalho e Desenvolvimento Social. Curitiba, 2014.

PASTANA, D. R., Estado punitivo e encarceramento em massa: retratos do Brasil atual. Revista Brasileira de Ciências Criminais. Vol. 77. p.313. Mar/2009. Disponível em: https://sag.fucamp.com.br/assets/professor/material_apoio/1092estadopunitivoeenca rceramentoemmassa.pdf. Acesso em: $01 \mathrm{dez} .2017$. 
OLIVEIRA, R. H. D. de; FIGUEIREDO, I. M. Z. A gestão da política de socioeducação no Estado do Paraná: repercussões no período de 2007 a 2015

PEREIRA, P. E. Juventudes pobres e a cidade: direitos violado, espaços negados. In LOPES, R. E., MALFITANO, A. P. S. (org) Terapia Ocupacional Social: desenhos teóricos e contornos práticos. São Carlos : EduFSCar, p. 345-350, 2016.

REIS, I. V. B. C. dos. Adolescente privado de liberdade: Análise da socioeducação no Estado do Paraná. Dissertação (Mestrado em Políticas Públicas). Universidade Estadual de Maringá - UEM, Maringá, 2012.

SAVIANI, D. A Pedagogia Histórico-Crítica, as lutas de classe e a educação escolar Germinal: Marxismo e Educação em Debate, Salvador, v. 5, n. 2, p. 25-46, dez. 2013. Disponível em: https://portalseer.ufba.br/index.php/revistagerminal/article/ view/9697/7085. Acesso em: 15 dez. 2016.

SECJ. Relatório de Gestão 2003-2010. Governo do Paraná. Curitiba, 2010. Disponível em: http://www.cedca.pr.gov.br/modules/conteudo/conteudo.php?conteudo=166. Acesso em 20 maio 2017.

SEDS. Plano de trabalho - Projeto técnico e plano de aplicação. Projeto Aproximando Famílias Curitiba (PR): 2013. Disponível em: www.crianca.mppr.mp.br/arquivos/.../projeto cedca aproximando familias 2013.pdf. Acesso em: 30 ago. 2017.

SEDS. Plano Estadual de Atendimento Socioeducativo - PR - SINASE. Curitiba - Pr, 2014. Disponível em:

http://www.cedca.pr.gov.br/arquivos/File/materiais/plano decenal socio.pdf. Acesso em: 20 maio 2017.

SEJU. Relatório de Ações Departamento de Atendimento Socioeducativo Paraná. 2015. Curitiba, 2015. Disponível em:

http://www.dease.pr.gov.br/arquivos/File/relatorio dease 2015.pdf. Acesso em: 20 maio 2017.

TABORDA, F. Semiliberdade: Monitorar, controlar e punir Engendrando os novos fluxos de controle. 324f. Dissertação (Mestrado em Ciências Sociais) - Universidade Estadual do Oeste do Paraná - UNIOESTE, Toledo, 2015. 


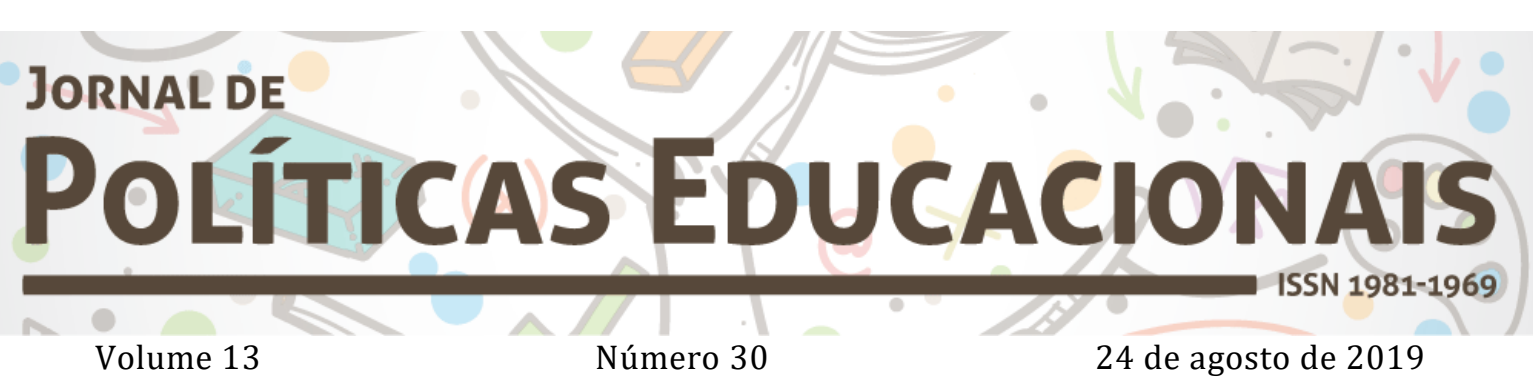

\begin{abstract}
(c)
SORAERIGHIS RESERVED O Copyright é retido pelo/a autor/a (ou primeiro co-autor) que outorga o direito da primeira publicação ao Jornal de Políticas Educacionais. Mais informação da licença de CreativeCommons encontram-se em http://creativecommons.org/licenses/by-nc-nd/2.5. Qualquer outro uso deve ser aprovado em conjunto pelo/s autor/es e pelo periódico.

JoRnAL DE Políticas EdUCACIONAIS é uma publicação do Núcleo de PolíticasEducacionaisdo Setor de Educação da Universidade Federal do Paraná - NuPE/UFPR, em consórcio com a Linha de Pesquisa em Políticas Educacionais do Programa de Pós-Graduação em Educação - PPGE/UFPR, que aceita colaboração, reservando-se o direito de publicar ou não o material espontaneamente enviado à redação. As colaborações devem ser enviadas ao NuPE/UFPR, conforme orientações contidas nas páginas do periódico na internet: http://revistas.ufpr.br/ipe.
\end{abstract}

\author{
Indexação: \\ BBE - Biblioteca Brasileira de Educação (MEC/INEP) \\ Clase (Base de Datos Bibliográfica de Revistas de Ciencias Sociales y Humanidades) \\ Diadorim - Diretório de Política de Acesso Aberto das Revistas Científicas Brasileiras (IBICT) \\ Google Scholar \\ Index Copernicus \\ Portal de Periódicos (CAPES) \\ SER - Sistema Eletrônico de Revistas da Universidade Federal do Paraná (SER/UFPR) \\ Sumários de Revistas Brasileiras (FUNPEC-RP) \\ DRII - Directory of Research Journals Indexing
}

(Periódico integralmente disponível apenas em via eletrônica)

Jornal de Políticas Educacionais / Núcleo de Políticas Educacionais da Universidade Federal do Paraná NuPE/UFPR - v.1, n. 1 (1ํs semestre de 2007) - Curitiba: NuPE/UFPR.

Volume 13, número 30 - Agosto de 2019

ISSN 1981-1969

1. Educação - Periódicos. 2. Política Educacional - Periódicos. I. NuPE/UFPR

Comitê Editorial:

Elisângela Scaff (UFPR)

Ana Lorena Bruel (UFPR)

Daniela de Oliveira Pires (UFPR)

Conselho Editorial:

Andréa Barbosa Gouveia (UFPR), Cesar Gernomino Tello (Universidad Nacional Tres Febrero, Argentina), Fernanda Saforcada (UBA), Gladys Beatriz Barreyro (USP), Gustavo Enrique Fischman, (Arizona State University), Jefferson Mainardes (UEPG), João Ferreira de Oliveira (UFG), Juca Gil (UFRGS), Luiz Souza 
OLIVEIRA, R. H. D. de; FIGUEIREDO, I. M. Z. A gestão da política de socioeducação no Estado do Paraná: repercussões no período de 2007 a 2015

Júnior (UFPB), Ney Cristina Monteiro de Oliveira (UFPA), Nicolás Bentancur, (Universidad de la República de Uruguay), Robert Verhine (UFBA), Rosana Cruz (UFPI), Rubens Barbosa Camargo (USP), Sebastián Donoso Díaz (Universidad de Talca, Chile), TheresaAdrião (UNICAMP), Vera Peroni (UFRGS).

Créditos e Agradecimentos:

Revisão de Língua Portuguesa, Abstract e Resumen: PROGRAMA DE APOIO ÀS PUBLICAÇÕES CIENTÍFICAS PERIÓDICAS DA UFPR

Arte e diagramação: TIAGO TAVARES (iagotav@gmail.com)

Jornal de Políticas Educacionais

Universidade Federal do Paraná

Setor de Educação

Núcleo de Políticas Educacionais - NuPE/UFPR

Avenida Sete de Setembro, 2645

$2^{\circ}$ andar, Sala 213

80.230-010 - Curitiba - PR - Brasil

Tel.: 41-3535-6264

jpe@ufpr.br

http://revistas.ufpr.br/jpe 